\title{
Main controlling factors and models of tight oil accumulation in Zhaoyuan area
}

\author{
Yanhua Fu \\ No.10 Oil Production Plant of Daqing Oilfield Co., Ltd., Heilongjiang Daqing 163000, China
}

\begin{abstract}
The study block opens up with the already found oil reservation, through the comprehensive analysis to seismic, well logging, well log and core data, collate and stipulate the system of fault, and then make sure the oil source fault; Meanwhile we make use of Geo-Office and Jason multiply technology, to launch micro faces and single sand body spread research. The result shows that, the study block mostly have 4 kinds of oil reservation: fault-lithologic, fault block, fault-screened and lithologic reservoir, the main target layer is Fuyu oil layer of Quantou Formation 3 and 4 part, the reservation and spread of oil is mainly controlled by the distance to the oil source, the space spread which is coordinated to form transportation system by fault concentrated belt and sand body, the high fault block trap. The oil reservation mainly exist in the internal part of fault concentrated belt and the sand body nearby, all in all the spread feature shows that the oil stays above and the water keeps low, and the formations which includes oil becomes less and less from the downstructure location to the updip ; The major period for hydrocarbon accumulation is the late period of the Mingshui Formation deposition; Here are the modes of the oil transformation and reservation : the oil goes downward and flow backward and transforms into Fuyu formation, which origins from the source rocks of Qingl member in Sanzhao depression, under the abnormal pressure through the source fault, and then the oil in Fuyu formation of Sanzhao depression transforms to study block under the affect of floatage along the two fault concentrated belt which was linked up by the sand body, at the upstructure location lithology or fault aligns with lithology forms the trap which keeps together to oil reservation .
\end{abstract}

Keywords: Master control factor; reservoir modes.

\section{Introduction}

The research block is located in the northern Songliao Basin. The target layer is the Fuyu reservoir of the third and fourth member of Quantou Formation, which shows good exploration prospects and one of the important replacement areas for reservoir increase and production. Through the anatomy of the reservoirs have been found and combined with the accumulation conditions, analysis of the research block oil and gas distribution and accumulation process, summarizes control the main controlling factors of hydrocarbon accumulation in the study blocks, It is of great significance to establish the corresponding hydrocarbon accumulation mode for the strategic deployment of oilfield exploration and development.

\section{Geological background of oil field}

The study block is located on the nose structure in the wings of a terrace. The main extension direction of the structure is NNE, and the overall performance is a monocline structure dipping in the NW direction. The block is on the slope of transition from depression to inversion tectonic belt, and the inversion strength is characterized by "strong in the east and weak in the west, strong in the south and weak in the north" [1-3]. In the area, the main oil-bearing strata are Cretaceous, and the oil-bearing strata are mainly distributed in Fuyu reservoir of the third and fourth member of Quantou Formation.

\section{Reservoir type and oil distribution}

The oil field types and productivity characteristics of the block are analyzed. There are four types of reservoirs in this area: fault-lithologic, fault block, fault-screened and lithologic reservoir. Fault-lithologic and fault block reservoirs are the most, mainly distributed in the upper sections of Fuyu reservoir. According to the analysis of reservoir profile and oil-bearing horizon distribution map, the overall distribution of oil-water in the longitudinal direction is characterized by the distribution of oil-water, and the oil-bearing horizon varies from the low part of the structure to the high part of the structure, and there is no unified oil-water interface in the whole area affected by faults and lithology changes. The oil layer is mainly 
distributed in the first group of Fuyu reservoir, and locally there are the oil-water layer and water layer. The second group of Fuyu reservoir and the lower formation are mainly composed of the oil-water layer and water layer, and the oil layer is locally developed. Plane reservoir is mainly distributed in the structural slope site, followed by the structural high part, affected by the dense fracture belt and sand body distribution, reservoir is mainly distributed in the dense fracture belt within and near in the sand body, and two fracture density distribution obviously different reservoir types, east fracture density in addition to the development of a small amount of lithologic reservoir, lithologic reservoir in fault is given priority to. Besides fault-lithologic reservoirs, fault blocks, fault-screened and lithologic reservoirs are also developed in the western fault dense zone.See Fig.1.
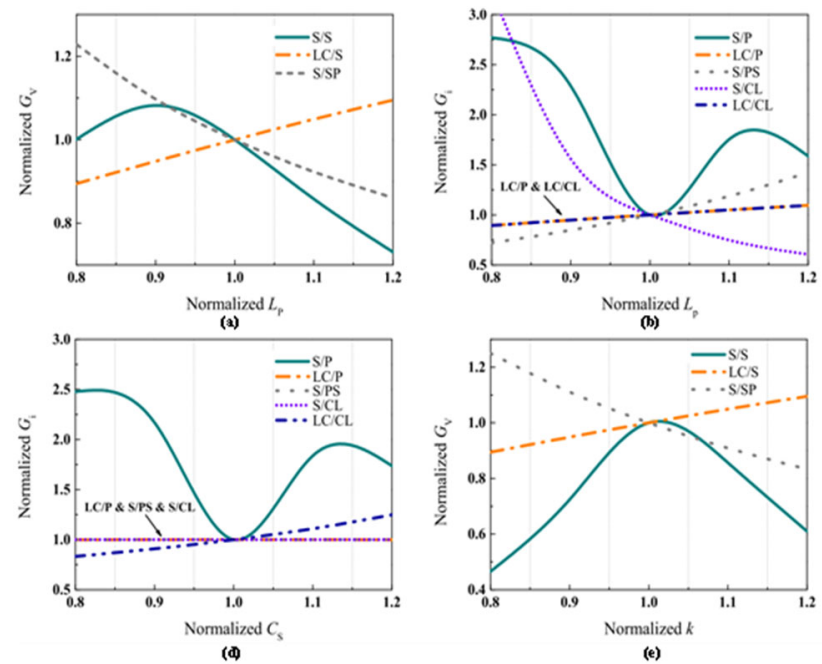

Fig.1 Reservoir type and oil distribution

\section{Main controlling factors of oil accumulation}

\subsection{Hydrocarbon source conditions are the material basis for oil accumulation}

The oil source correlation results which consider Sanzhao depression position relationship show that the oil in Fuyu reservoir from Qingl member in Sanzhao depression, the oil under the action of overpressure is generated through the source fracture into Fuyu reservoir by "backward" migration, then under the effect of buoyancy formed by fault and sand body with lateral conducting channel to study blocks, formed accumulation when meet effective traps, the oil distribution along the way. The oil of study blocks in Fuyu reservoir is mainly distributed in the migration of slopes, a few distribution in constructing the high place, the distribution results show that the oil source is insufficient, the closer distance from oil source, the more beneficial to oil accumulation, the more oil accumulation horizon. See Fig. 2.
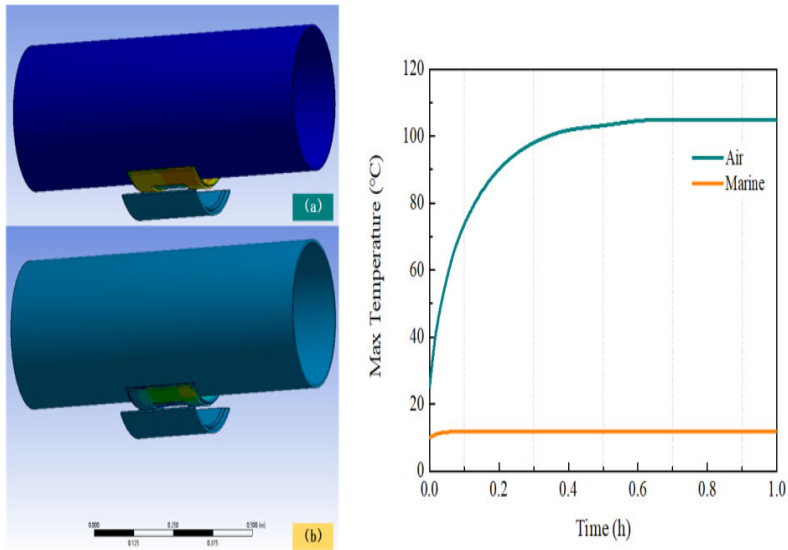

Fig. 2 the material basis for oil accumulation

\subsection{The transport system determines the migration path of oil}

The faults in the study block mostly strike north-south, forming two fault concentrated belt, and presenting a "box-shaped" anticline combination on the profile. The internal faults of Fuyu reservoir were strongly active in the early deposition of Qingshankou Formation and the late deposition of Mingshui Formation, and the structure began to reverse in the late deposition of Nenjiang Formation, which is conducive to the formation of structural traps such as fault blocks and fault anticlines. Geo-office and Jason Integrated well and ground seismic exploration technology are used to predict the channel complex sand body, and the results show that the sand body is banded in the direction of SW to NE. Fault zone and channel sand body cooperate to form effective oil transport channel and oil trap. Oil migrates laterally along the transport channel and accumulates to form reservoirs. If the farther the transport channel extends, the farther the oil migrates laterally and accumulates in the area far from the oil source. And vice versa. In addition, oil accumulation is also affected by the distance from the oil source. For Wells far away from the oil source, although there are transport channels and traps, due to the lack of oil source, there may be no oil accumulation.See Fig.3.

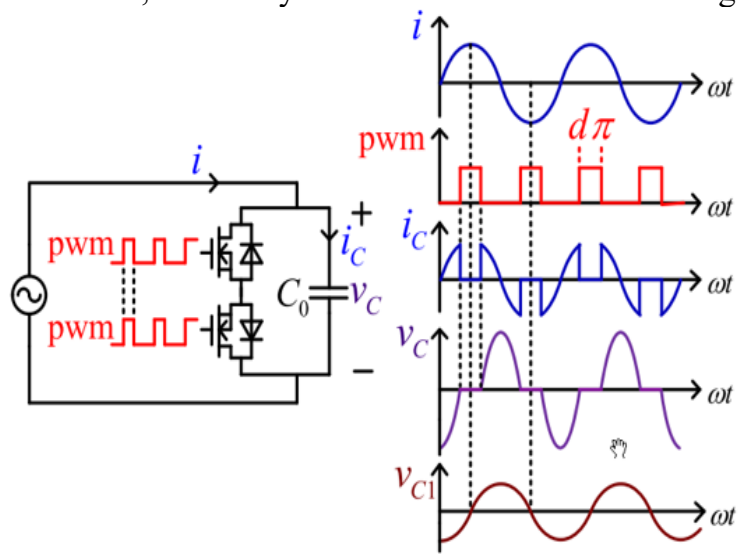

Fig.3 The transport system determines the migration path 


\subsection{High fault block trap is the main place for oil accumulation}

Oil accumulation in this area is not only controlled by migration and transport channels, but also controlled by traps. If there are further traps connected by transport channels, oil accumulation can be formed. Fuyu reservoir in the study block has the largest number of oil Wells and the highest productivity in horst structure, followed by fault step structure, graben structure, and most of the Wells have low productivity. From the perspective of reservoir types, fault-lithologic traps and fault block traps have the largest amount of oil accumulation, while faultscreened and lithologic traps are relatively less.

Aiming at the problems of large starting current and bus voltage drop when three-phase asynchronous motor starts, a soft starting control system for heavy-load starting is designed. First of all, based on the motor control theory, the pulse generation module, three-phase voltage regulation module and PID closed loop are built, and the soft start control system is designed to control the terminal current and voltage of the asynchronous motor. Secondly, based on the Simulink software, according to the actual data of the feed water pump motor of a coal-fired unit in Heilongjiang Province, the soft start control model is built and simulated. Finally, the field test is carried out, and the test results are similar to the simulation results. The results show that the model can effectively limit the starting current of asynchronous motor and reduce the influence of feedwater pump motor start-up on other equipment on the busbar under the condition of heavy load starting. It provides a reference for the heavy-load start-up of the asynchronous motor.

\section{Accumulation model}

The period of hydrocarbon accumulation should be controlled by the period of hydrocarbon expulsion of source rocks, the period of fault activity and the period of trap formation. The hydrocarbon generation and expulsion history of source rocks in Qingl member of Sanzhao depression shows that hydrocarbon generation began at the end of Nenjiang Formation, and reached the peak at the end of Mingshui Formation, paleogene and Neogene. The study on the history of fault activity shows that the faults in Fuyu reservoir in this area began to be active at the end of Nenjiang Formation, Mingshui Formation and Paleogene deposition, and became the transport channel of oil migration. The study of structural trap to reservoir formation in this area shows that the time of structural inversion of Fuyu reservoir is at the end of Nenjiang Formation deposition, and is fixed at the end of Mingshui Formation deposition. Therefore, based on the above analysis, it can be concluded that the main period of oil accumulation of Fuyu reservoir in the study area should be at the end of Mingshui Formation deposition. See Fig.4 and Fig.5.

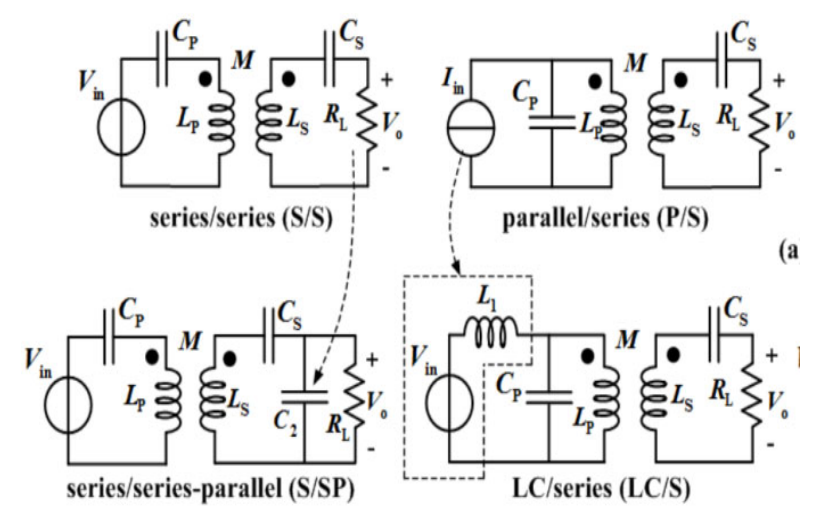

Fig.4 Accumulation model 1

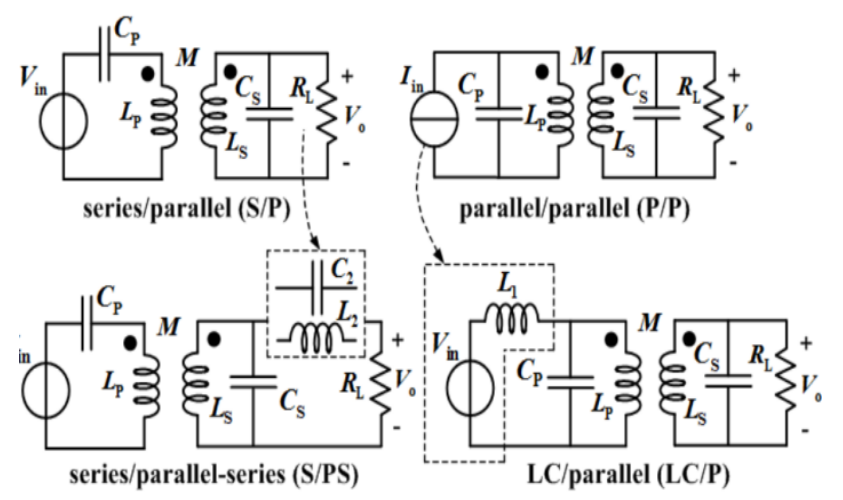

Fig.5 Accumulation model 2

Depending on the type of the reservoir and oil accumulation research on main controlling factors and accumulation period, patterns can be summarized: the oil goes downward and flow backward and transforms into Fuyu formation, which origins from the source rocks of Qingl member in Sanzhao depression, under the abnormal pressure through the source fault, and then the oil in the Fuyu formation of Sanzhao depression transforms to study block under the affect of floatage along the two fault concentrated belt which was linked up by the sand body , at the upstructure location lithology or fault aligns with lithology forms the trap which keeps together to oil reservation. See Fig.6. 


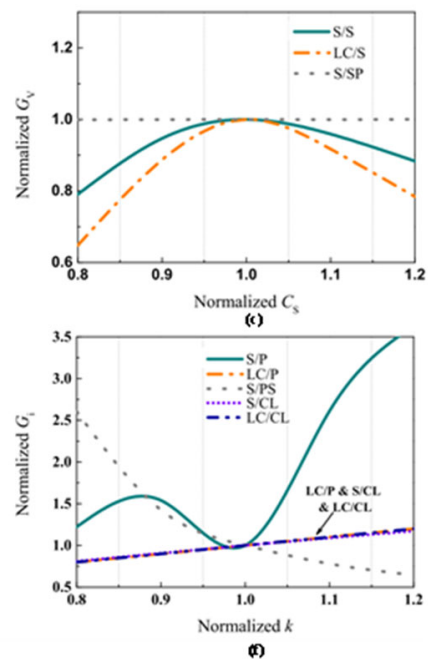

Fig.6 Reservoir type oil distribution of Sanzhao depression transforms to study block

Forming fault-lithologic, fault block, fault-screened and lithologic reservoir. Fault-lithologic and fault-block reservoirs are the most abundant, mainly distributed in horst blocks and fault terraces, and a small amount in graben blocks.

\section{References}

1. N. Yi, Q. Wang, L. Yan, et al., A multi-stage game model for the false data injection attack from attacker's perspective. Sustainable Energy Grids \& Networks 28 (2021).

2. Xu Jianjun, Huang Lida, Yan Limei, Yi Na. Insulator Self-Explosion Defect Detection Based on Hierarchical Multi-Task Deep Learning[J]. Transactions of China Electrotechnical Society, 2021,36(07):1407-1415.

3. Limei,LIU Yongqiang,XU Jianjun,et al.Broken string diagnosis of composite insulator based on Grabcut segmentation and filler area discrimination[J].Power System Protection and Control,2021,49(22):114-119

4. $\mathrm{Na}$ Yi,Jianjun Xu,Limei Yan,Lin Huang. Task Optimization and Scheduling of Distributed Cyberphysical System Based on Improved Ant Colony Algorithm. Future Generation Computer Systems, 109(Aug. 2020), 134-148.

5. Yang Zhao, Jianjun $\mathrm{Xu}$, Jingchun Wu. A New Method for Bad Data Identification of Oilfield Power System Based on Enhanced Gravitational SearchFuzzy C-Means Algorithm. IEEE Transactions on Industrial Informatics. VOL. 15, NO. 11, NOVEMBER 2019 5963-5970

6. Xu, J., Huang, L., Yin, S. et al. All-fiber self-mixing interferometer for displacement measurement based on the quadrature demodulation technique. Opt Rev. 2018,25(1):40-45. 